\title{
The Interaction of Human Enteric Pathogens with Plants
}

\author{
Jeong-A Lim, Dong Hwan Lee and Sunggi Heu* \\ Division of Microbial Safety, National Academy of Agricultural Science, Rural Development Administration, Suwon 441- \\ 707, Korea
}

(Received on April 15, 2014; Revised on May 10, 2014; Accepted on May 10, 2014)

There are an increasing number of outbreaks of human pathogens related to fresh produce. Thus, the growth of human pathogens on plants should be explored. Human pathogens can survive under the harsh environments in plants, and can adhere and actively invade plants. Plant-associated microbiota or insects contribute to the survival and transmission of enteric pathogens in plants. Human enteric pathogens also trigger plant innate immunity, but some pathogens-such as Salmonel$l a$-can overcome this defense mechanism.

Keywords : defense, human enteric pathogens, plant innate immunity

Recently, numerous food-borne illness outbreaks have been associated with fresh produce. This increase in produce contamination may be caused by 1) people consuming more fresh produce, 2) long-term storage and transportation of fresh produce, and 3) frequent import and export of fresh produce from/to foreign countries. These outbreaks are also associated with the interaction of human enteric pathogens with plants and the plant environment. Numerous studies have examined the survival, internalization and interaction of human pathogens on/in and with plants. The majority have focused on postharvest microbial contamination rather than contamination in the field. However, few studies have examined the fitness of human enteric pathogens on plants, and it is believed that human enteric pathogens adapt well to plant environments. This report explores the interaction of human enteric pathogens with plants and the plant environment.

Survival of enteric pathogens in the agricultural environment

*Corresponding author.

Phone) +82-31-290-0455, FAX) +82-31-290-0407

E-mail) sunggiheu@korea.kr
The epidemiology of food-borne illness has changed significantly over the last two decades. More frequent outbreaks of enteric foodborne pathogen changed the sources of contamination from processed food to animal reservoirs, soils, irrigation water and fresh produce.

In soils. Enteric pathogens can be introduced into fields by applying inadequately composted or raw animal manure or sewage onto soil (Natvig et al., 2002). The feces of wild animals is also a source of contamination. Many foodborne pathogens can survive in soil. Typically, the population sizes of enteric pathogens in soil have decreased. Although the conditions for survival of enteric pathogens in soil are thought to be less favorable than in the intestinal system, pathogens have been found to survive for several days to almost a year in soil. Although the role of soil as a reservoir of specific bacterial pathogens has been explored, recent studies have demonstrated that soil may have a larger role in the transmission of enteric diseases than previously believed. Survival in soil as a mixed matrix is critical since mobilization of pathogens to root crops or splash of contaminated soil particles onto aerial plant tissues is possible.

The enteric pathogen Escherichia coli $\mathrm{O} 157: \mathrm{H} 7$ has been found in birds, cattle, deer, dogs, horses, sheep, and swine. The feces of these animals can transmit E. coli $\mathrm{O} 157: \mathrm{H} 7$ into soil, and the soil type affects the persistence of $E$. coli. $E$. coli survival had been examined in soil of three different textures; sandy soil, loamy soil, and a loamy sand soil. Sand soil is known to be optimal for E. coli survival. Temperature and moisture also affected the survival of $E$. coli in soil. At lower temperatures $\left(25^{\circ} \mathrm{C}\right)$ and high soil moisture $(100 \%), E$. coli could survive for more than 80 days (Cools et al., 2001). Gagliardi and Karns reported that E. coli O157:H7 cells persisted longer in the soil in the presence of Rye and Alfalfa roots. However, the roots of other plants had no effect, and the rhizosphere effect phenomenon on the soil bacterial population is plant species specific (Gagliardi and Karns, 2002). However, waste type has a sig- 
nificant effect on the survival of $E$. coli $\mathrm{O} 157: \mathrm{H} 7$ in wasteamended soil (Williams et al., 2007). After the survival and acquisition of nutrition in soil, some $E$. coli strains produce filamentous structures that extend from the cell surface to facilitate cell attachment to the surface of the plant. Thus, $E$. coli originating from the soil may colonize plants such as radish and lettuce.

Salmonella is commonly detected in environmental soil samples collected from agricultural areas (Thomason et al., 1977). Salmonella may enter the soil environment from various sources; manure being the most common. Salmonella can be widely disseminated in soil even in the absence of active fertilization as a result of water currents, underground springs, and rain runoff carrying contaminated material. After introduction into the soil, Salmonella survival is influenced by temperature, soil type, and the presence of protozoa (Jacobsen and Bech, 2012). Salmonella survival was greater in soil containing poultry compost than in soil containing dairy cattle manure compost (Islam et al., 2004). In contrast to E. coli, Salmonella can survive and multiply for at least 1 year in soil environments. S. enterica is known to contaminate carrots, radish, lettuce and parsley following treatment with contaminated manure compost or irrigation water (Islam et al., 2004).

Campylobacter jejuni was cultured from radish roots and the spinach rhizosphere for at least 23 and 28 days, respectively, at $10^{\circ} \mathrm{C}$. This enteric pathogen also persisted in the rhizosphere of spinach for prolonged periods of time at $16^{\circ} \mathrm{C}$, a temperature at which many cool-season crops are grown. The enhanced survival of $C$. jejuni in soil and in the rhizosphere may play an important role in its contamination cycle in the environment, and may be associated with the sporadic $C$. jejuni incidence and campylobacteriosis outbreaks associated with produce (Brandl et al., 2004).

Soil particles are believed to serve as micro-ecological niches for bacteria that provide a high concentration of nutrients due to the release of organic molecules. The adhesion of enteric pathogen cells to soil particles is important for the survival of pathogens in soil, and is affected by many factors such as surface charge, wettability, surface texture, and diversity of different soil types. In general, the adhesion of enteric pathogens to highly moisturized sandy soil correlates with cell surface hydrophobicity, and the positive charge of the cell surface contributes to the adhesion process (Stenström, 1989).

In plants. A variety of enteric pathogens have been isolated from fresh fruits and vegetables, including $S$. enterica, Listeria monocytogenes, E. coli, Shigella spp., Campylobacter spp., Yersinia spp., and Staphylococcus aureus.
The contact of enteric pathogens with the flowers, stems or fruits of plants leads to infiltration and colonization of plant tissues. Enteric pathogens are not normally considered part of the phyllosphere microbial population. However, this notion is being refuted based on the recent outbreaks of food-borne illness.

Many studies have explored the survival of enteric pathogens on plants. The survival of enteric pathogens in the phyllosphere is affected by nutrition from plants, UV irradiation, toxic compounds from plants and desiccation. The majority of studies have focused on E. coli and Salmonella sprayed or applied directly onto the plant foliage. When applied directly to foliage, E. coli and Salmonella can survive on parsley in the field for 177 and 231 days, respectively (Islam et al., 2004). After spraying lettuce plants with $E$. coli $\mathrm{O} 157: \mathrm{H} 7$ contaminated water, the pathogen could be recovered from foliage after 30 days (Solomon et al., 2003). The recovery of $E$. coli $\mathrm{O} 157: \mathrm{H} 7$ was greater from foliage contaminated with sprinkler irrigation than with drip irrigation. The lettuce leaves remained contaminated with E. coli $\mathrm{O} 157: \mathrm{H} 7$ even after washing, indicating that spray irrigation of vegetables with contaminated water may result in internal colonization of enteric pathogens into plant tissue (Solomon et al., 2002).

The epiphytic fitness of $S$. enterica has been assessed on cilantro plants (Brandl and Mandrell, 2002). The population sizes of two plant-associated bacteria, Pantoea agglomerans and Pseudomonas chlororaphis, were 10-fold higher than the human pathogen at $22^{\circ} \mathrm{C}$. However, S. enterica serovar Thomson achieved significantly higher population levels and accounted for a higher proportion of the total culturable bacterial flora on cilantro leaves when the plants were incubated at warm temperatures, such as $30^{\circ} \mathrm{C}$. E. coli $\mathrm{O} 157: \mathrm{H} 7$ showed greater survival on the abaxial (under) side of the leaves than on the adaxial (upper) side. The survival of enteric pathogens in the phyllosphere may be associated with biofilm formation. Biofilm formation by enteric pathogens on leaf surfaces may facilitate survival in the harsh phyllosphere environment, which is exposed to UV irradiation and desiccation, and protect bacteria from dissemination using sanitizers (Morris and Monier, 2003).

Six human pathogens have been recovered from the phyllosphere of cantaloupe, lettuce and pepper under controlled environmental conditions 2 weeks after inoculation with pathogens (Stine et al., 2005). This suggested that contamination of human pathogens on edible vegetables immediately before harvest could result in a significant food safety hazard.

Plant tissue damage can promote the rapid multiplication of E. coli $\mathrm{O} 157: \mathrm{H} 7$ on lettuce. The population size of 
E. coli $\mathrm{O} 157: \mathrm{H} 7$ after a 4-h inoculation increased by 4-, 4.5-, and 11-fold on lettuce leaves that were mechanically bruised, cut into large pieces, and shredded into multiple pieces, respectively. Thus, various types of plant tissue damage after harvest or during processing promote the multiplication of E. coli O157:H7 (Brandl, 2008).

\section{Interaction with other plant pathogens or insects}

Pre-existing microbiota or insects may influence the survival or growth of enteric pathogens on plants. Plantassociated microbiota may either promote or inhibit the establishment of enteric pathogens on plants.

Plant pathogens. Plant diseases change the phyllospheric atmosphere and enhance the growth of enteric pathogens. Co-inoculation of Pectobacterium carotovorum subsp. carotovorum with $S$. enterica or E. coli O157:H7 increased Salmonella or E. coli O157:H7 levels by more than 10fold compared to the absence of co-inoculation (Wells and Butterfield, 1997). Fungal rot caused by Botrytis and Rhizopus also enhanced the growth of Salmonella on potato, carrots, and pepper in the marketplace (Wells and Butterfield, 1999). The presence of Xanthomonas campestris pv. vesicatoria on co-colonized tomato plants had no effect on the incidence of $S$. enterica tomato phyllosphere contamination. However, the growth of S. enterica in the tomato phyllosphere was observed in co-colonized plants in the absence of plant disease (Barak and Liang, 2008). Eastern shore Virginia (ESV) tomato cultivars were inoculated with Ralstonia solanacearum alone and $R$. solanacearum with Salmonella. An increased amount of $S$. enterica was recovered from tomato inoculated with $R$. solanacearum and Salmonella than from tomato inoculated with Salmonella alone. It was suggested that $R$. solanacearum influences $S$. enterica survival and transportation through the internal tissues of tomato plants (Pollard et al., 2014). In addition to plant pathogens, resident bacteria such as $P$. syringae and Erwinia herbicola enhanced the survival of $S$. enterica on leaves. Viable populations of $S$. enterica applied to plants pre-inoculated with $P$. syringae or either of two E. herbicola strains increased by more than 10 -fold compared to control plants that were not pre-inoculated (Poza-Carrion et al., 2013). It has been suggested that the presence of common epiphytic bacteria on plants can protect immigrant bacteria such as Salmonella from desiccation on leaf surfaces. Recently, Potnis et al. reported that the suppression of pathogen-associated molecular pattern (PAMP)-triggered immunity by a virulent $X$. perforans strain induces effector- triggered susceptibility to create a friendly environment for S. enterica persistence in the tomato phyllosphere. However, the activation of effector-triggered immunity by an avirulent $X$. perforans strain reduced the $S$. enterica population (Potnis et al., 2014). Many studies have suggested that the presence of other microbes facilitate the colonization of enteric pathogens on harsh leaf environments, but the presence of the enteric pathogen $S$. enterica reduced $P$. carotovorum subsp. carotovorum populations and soft rot progression by moderating local environmental $\mathrm{pH}$ (Kwan et al., 2013).

However, the rhizosphere may have a different environment than the phyllosphere. The population of Salmonella and E. coli $\mathrm{O} 157: \mathrm{H} 7$ was 1000 -fold lower in non-autoclaved soil, suggesting that enteric pathogens compete with indigenous epiphytes in the soil (Cooley et al., 2003).

Insects. Insects are another potential source of contamination, and bacteria have evolved to exploit insects as hosts or vectors. Several plant pathogenic bacteria in the family Enterobacteriaceae, which includes Salmonella and E. coli $\mathrm{O} 157: \mathrm{H7}$, are known to use insects as vectors for long distance transmission (Nadarasah and Stavrinides, 2011). Devastating P. carotovorum subsp. carotovorum can survive in the gut of the fruit fly Drosophila and can be transferred to other plants. Similar to plant pathogenic bacteria, under laboratory conditions contaminated flies can directly transfer enteric bacteria to plant leaves or fruits. $E$. coli $\mathrm{O} 157: \mathrm{H} 7$ acquired by flies from contaminated cattle manure and deposited in regurgitation spots on spinach leaves can survive and multiply. Regurgitation spots serve as a nutrition source, allowing E. coli $\mathrm{O} 157: \mathrm{H} 7$ to survive on the spinach phyllosphere (Wasala et al., 2013). This hypothesis was supported by Soto-Arias et al. (Soto-Arias et al., 2013). Phytophagous insects influence the population dynamics of $S$. enterica in agricultural crops. Areas of infested leaves with feeding damage sustained higher $S$. enterica populations than areas without damage on plants infested with phytophagous insects, such as Frankliniella occidentalis.

In addition to the effect of insect feeding on the survival or transfer of enteric pathogens on plants, insect excrements were also involved in the dissemination of pathogens on plants. Semenov et al. demonstrated that feeding of infested cress shoots to grape snails resulted in colonization of $S$. enterica Typhimurium and E. coli O157:H7 up to $10^{5} \mathrm{CFU} / \mathrm{ml}$ per dry snail excrement (Semenov et al., 2010). In addition to the movement of the contaminated insect, its excrement can spread enteric pathogens from plants to the ground. 
Genes involved in the attachment and internalization of enteric pathogens in plants

Enteric pathogens, especially Salmonella spp., have adapted to survive in the plant environment. Enteric pathogens prefer to attach to cut surfaces or natural openings-such as stomata-using appendages such as pili, fimbriae, curli and cellulose. Therefore, several genes are important for adaption to plant environments, and are involved in attachment, invasion and internalization.

Attachment. It has been shown that diverse serotypes of $S$. enterica actively attach to plant tissue (Saggers et al., 2008). Among them, $S$. Tennessee (which produces biofilm) attached more efficiently to cabbage and lettuce leaves than other serovars (Patel and Sharma, 2010). The extracellular matrix, including cellulose, capsule, and fimbriae, are required for Salmonella attachment. The S. enterica Enteritidis mutant lacking bcsA (cellulose synthase) colonized alfalfa sprouts to lower levels than the wild-type, and the ability was restored when $b c s A$ was expressed from a plasmid (Barak et al., 2007). Another mutant lacking yihO (O-antigen capsule assembly and transport) also showed reduced attachment (Barak et al., 2007). In other reports, transposon mutants of $S$. enterica Newport (which shows low attachment to alfalfa sprouts) were screened (Barak et al., 2005). Transposon insertion sites of the selected mutants were present in the intergenic region between $a g f B$ (the surface-exposed aggregative fimbria nucleator) and $a g f D$ (a transcriptional regulator of the LuxR superfamily), as well as $r p o S$ (the global stress regulator). In S. enterica, it is known that rpoS plays an important role in biofilm formation and adhesin regulation (Prigent-Combaret et al., 2001, Raina et al., 1993). It was confirmed that RpoS is required for initial attachment to plant tissue. AgfD regulates curli, cellulose production and $\mathrm{O}$-antigen capsule, which are required for multicellular behavior (Romling et al., 1998). In addition, when $S$. enterica Typhimurium presents the rdar morphotype which was positively regulated by AgfD, its survival improved in tomato leaves (Gu et al., 2011). Based on a study in E. coli, pathogenic strains-including diarrheagenic $E$. coli-bind to several plants such as alfalfa, tomato, and Arabidopsis thaliana (Jeter and Matthysse, 2005). However, laboratory strain K12 (which do not generate curli) could not bind to plant surfaces. Expression by K12 strains of curli biosynthesis genes ( $\mathrm{mlrA}$, a positive regulator of curli biosynthesis or $\operatorname{csg} A-G$ operon, involved in curli biosynthesis) enabled binding to sprouts.

Internalization. Attached enteric pathogens can invade internal parts of plant tissue through natural apertures such as stomata and damaged tissue (Erickson, 2012). Internalization of pathogens was observed by microscopy (Franz et al., 2007) and enumeration after disinfectant treatment (Klerks et al., 2007). Kroupitski et al. reported that internalization of $S$. enterica in leaves was associated with motility and chemotaxis (Kroupitski et al., 2009). The flagella mutants $(f l i G H I:: T n 10)$ deficient in motility showed reduced attachment and penetration of lettuce leaves. Entry of the cheY mutant defective in chemotaxis was also inhibited. In addition, they hypothesized that photosynthesis products play a role as an attractive nutrient. In other reports, it was shown that the type III secretion system (TTSS) of shigatoxigenic E. coli (STEC) O157:H7 is required for successful colonization within the stomata of leaves (Saldana et al., 2011). The number of TTSS escN mutants colonized within the stomata decreased, and non-pathogenic K12 strains harboring a plasmid expressing the enterocyte effacement (LEE) pathogenicity island (the TTSS and effector genes) were more efficiently internalized.

Movement. Internalized enteric pathogens at root sites can be detected in leaves or fruit. When lettuce plants were cultivated in a hydroponic system containing E. coli $\mathrm{O} 157: \mathrm{H} 7$ or $S$. Typhimurium, or in potting soil irrigated with pathogens containing water, the enteric pathogens were found in surface-sterilized lettuce leaves (Franz et al., 2007; Nthenge et al., 2007). Yaron et al. explored whether the biofilm matrix played a role in survival of $S$. typhimurium on parsley and enhanced the mobility of the $S$. typhimurium in the parsley plants (Lapidot et al., 2006; Lapidot and Yaron, 2009). S. typhimurium added to irrigation water could penetrate the roots and translocate to the leaves or stems. However, when the number of double mutants, which lack the ability to synthesize cellulose and curli due to the lack of $b c s A$ (cellulose synthesis A) and $a g f B A$ (curli subunit genes A and B), were translocated to leaves, their population was one order of magnitude lower than the wild-type strain.

\section{Activation of plant defenses by enteric pathogens}

Many studies have suggested that enteric pathogens can invade and be internalized into plants, although they are not plant pathogens. For successful colonization, enteric pathogens must overcome the plant basal defense system and innate immune system.

Plant innate immunity. Plants respond to infection using the innate immune system. This consists of two main branches: PAMP-triggered immunity (PTI) and effector- 
triggered immunity (ETI). In PTI, pathogen- or microbeassociated molecular patterns (PAMPs or MAMPs) are recognized by plant receptors known as pattern recognition receptors (PRRs). PTI respond to molecules common to many classes of microbes including non-pathogens. Upon recognition, plant defense signal pathways are activated, and among those, jasmonate, salicylic acid and ethylene play an important role. Virulent pathogens can overcome PTI through diverse strategies such as the production and secretion of effectors, resulting in effector-triggered susceptibility (ETS). For incompatible interactions, effectors produced and released by the pathogen are transferred into the plant cell through the TTSS. These effectors are recognized by specific nucleotide-binding leucine-rich-repeat (NB-LRR) proteins encoded by resistance genes, resulting in ETI and limitation of pathogen spread to other tissues. PTI is considered the first line of defense against microbial infection, while ETI is an accelerated and amplified response. The outcome of the rapid response is often a hypersensitive response (HR) (Jones and Dangl, 2006; Spoel and Dong, 2012).

The archetypal elicitor of PTI is bacterial flagellin. Flagella are important for bacterial motility. A synthetic 22-amino-acid peptide (flg22) from a conserved flagellin domain is sufficient to induce PTI. Using a genetic screen of Arabidopsis plants, FLS2 (LRR-receptor kinase) was defined as a receptor for flg22 (Chinchilla et al., 2006). Flagellin from diverse bacteria-including plant pathogensshowed different induction efficiencies against Arabidopsis FLS2. Flagellin from Agrobacterium tumefaciens is less active for FLS-mediated PTI induction than that from $P$. syringae (Felix et al., 1999). Flagella from E. coli O157:H7 and $S$. enterica also induce FLS2-mediated PTI. The population of an E. coli O157:H7 flagellar mutant was significantly greater than that of the wild type. This suggests that E. coli $\mathrm{O} 157: \mathrm{H} 7$ flagella were recognized by Arabidopsis plants, which reduced the bacterial population through FLS2-mediated PTI induction (Seo and Matthews, 2012). The Salmonella 14028 mutant lacks both flagellin genes (fliC and $f l i B$ ) fail to produce flagella, and this mutant showed significantly higher endophytic colonization (Iniguez et al., 2005). This suggests that Salmonella flagella are specifically recognized and induce PAMP-triggered plant defenses.

Stomata defense. Since bacteria cannot actively enter plants (unlike fungi), after attachment on the surface of plants they enter the plant cell through natural openings or wounds. The stomata are prevalent natural openings in the leaf epidermis that are crucial for gas exchange and recognized as a major entry point for bacteria. Recently, plant stomata have been shown to play an important role in host immunity and pathogen virulence (Zeng et al., 2010). Melotto and colleagues reported that plant stomata close in response to a plant pathogen, $P$. syringae pv. tomato (Pst DC3000), and a human pathogen, E. coli O157:H7 (Melotto et al., 2006). Stomata closure was also triggered by flg22 (a peptide derived from bacterial flagellin) and lipopolysaccharide (LPS), which are recognized by PAMPs or MAMPs, in a salicylic acid-dependent manner. For plant pathogens, virulence factors produced by plant pathogens overcome this innate immunity and disable stoma defense, but the human pathogen E. coli O157:H7 could not counter stomata defense and prolonged the activation of PAMPinduced stomata closure.

S. enterica serovar Typhimurium SL1344 responded to plants differently from E. coli $\mathrm{O} 157: \mathrm{H} 7$. The efficient entry of $S$. enterica into stomata within $2 \mathrm{~h}$ indicates that Salmonella did not induce stomata closure. Under light conditions, S. enterica aggregated near open stomata and migrated towards them, and entered plant tissue without triggering stomata closure. It remains unclear whether $S$. enterica overcomes or inhibits stomata defenses (Kroupitski et al., 2009). E. coli O157:H7 induced stronger plant immunity than did $S$. enterica. Thus, plants may recognize specific human pathogens more effectively than other pathogens.

Plants respond to human pathogens. When plants detect flagellated bacteria, they exclude bacteria by closing their stomata. If bacteria cannot overcome this stomata defense, they will remain on the harsh leaf surfaces. The recognition of flagellin by FLS2 is the first line of plant defense. Upon PAMP recognition of flagellin through PRRs, plant defense responses (including the activation of mitogenactivated protein kinase cascades (MAPK)) are followed by an enhanced expression of various pathogen-related (PR) genes (Schikora et al., 2008). The expression of the pathogen-related genes PR1, PR4 and PR5 was induced by $S$. enterica infection of lettuce (Klerks et al., 2007). Transcriptome analysis was performed on Arabidopsis infected with Salmonella, E. coli DH5 $\alpha$ and P. syringae pv. tomato strain DC3000. A total of 249 genes showed differential expression after infection by Salmonella. Among these, 24 genes were induced and 11 were down-regulated after Salmonella infection. A total of 164 genes showed strong differential expression by all three bacteria. Transcription factors WARKY22, WARKY33, WARKY40, WARKY43, WARKY53, bZIP5, and bZIP60, as well as a number of protein kinases and phosphatases were included in this 
group. A large number of defense-related genes respond to both pathogenic and nonpathogenic bacteria, but specific groups of genes were regulated by Salmonella infection (Schikora et al., 2011).

Salmonella can infect various Arabidopsis tissues and proliferate in apoplastic compartments, resulting in wilting and chlorosis (Schikora et al., 2008). Lettuce plants infected with Salmonella showed reduced root formation, stunted growth and yellow spots on the leaves. However, leaves infected or infiltrated with $E$. coli O157:H7 showed no obvious effects and the bacteria neither multiplied nor died (Thilmony et al., 2006). These phenotypic changes can be explained by the stronger induction of plant immune response by E. coli O157:H7 than by Salmonella, and suppression of the immune response by Salmonella. Expression of the PR1 gene was significantly higher in Arabidopsis leaves infected with E. coli O157:H7 compared to those infected with $S$. enterica (Roy et al., 2013). Suppression of the plant defense response by Salmonella has been reported. Salmonella harbors two TTSSs: TTSS-1 and TTSS2, encoded by the Salmonella pathogenicity island (SPI). TTSSs of Salmonella play a key role in transferring effectors to animals, similar to plant pathogens. Plant pathogenic bacteria use the TTSS to translocate effectors into the plant cell and suppress plant immunity. The population of TTSS mutants of Salmonella was much lower than that of the wild type and induced stronger symptoms in plants. Mutation of invA or $\mathrm{prgH}$ in Salmonella leads to malfunction of the TTSS, and these mutants show reduced suppression of plant defense responses (Schikora et al., 2012; Schikora et al., 2011; Shirron and Yaron, 2011). Therefore, S. enterica (but not E. coli $\mathrm{O} 157: \mathrm{H} 7$ ) interacts with plants and is thought to be a plant endopathogen (Schikora et al., 2008).

\section{Concluding remarks}

Based on the growing number of human pathogenic bacteria outbreaks related to agricultural produce, the adaptation of enteric pathogens to plant invasion should be explored. Previous studies have demonstrated that enteric pathogens contain many genes involved in attachment to plants and adaption to plant environments. Based on recent reports, Salmonella adapts to the plant environment more actively than E. coli O157:H7. Although both E. coli $\mathrm{O} 157: \mathrm{H} 7$ and $S$. enterica induce plant innate immunity, Salmonella overcomes this defense by producing effectors to suppress immunity, but $E$. coli $\mathrm{O} 157: \mathrm{H} 7$ induces a prolonged immune response without suppression. Salmonella survives and multiplies in the plant environment, but to a considerably lower level than plant pathogens. It is not easy to call Sal- monella as a plant pathogen now, but a series of evolutionary events in Salmonella genes to improve adaption to the plant environment will make plant for their host.

\section{Acknowledgments}

This work was supported by the Rural Development Administration (RDA) fund (PJ008751), and J. Lim and D. Lee have postdoctoral fellowships from the RDA.

\section{References}

Barak, J. D., Gorski, L., Naraghi-Arani, P. and Charkowski, A. O. 2005. Salmonella enterica virulence genes are required for bacterial attachment to plant tissue. Appl. Environ. Microbiol. 71:5685-5691.

Barak, J. D., Jahn, C. E., Gibson, D. L. and Charkowski, A. O. 2007. The role of cellulose and O-antigen capsule in the colonization of plants by Salmonella enterica. Mol. Plant Microbe Interact. 20:1083-1091.

Barak, J. D. and Liang, A. S. 2008. Role of soil, crop debris, and a plant pathogen in Salmonella enterica contamination of tomato plants. PLoS ONE 3:e1657.

Brandl, M. 2008. Plant lesions promote the rapid multiplication of Escherichia coli O157: H7 on postharvest lettuce. Appl. Environ. Microbiol. 74:5285-5289.

Brandl, M. T., Haxo, A. F., Bates, A. H. and Mandrell, R. E. 2004. Comparison of survival of Campylobacter jejuni in the phyllosphere with that in the rhizosphere of spinach and radish plants. Appl. Environ. Microbiol. 70:1182-1189.

Brandl, M. T. and Mandrell, R. E. 2002. Fitness of Salmonella enterica serovar Thompson in the cilantro phyllosphere. Appl. Environ. Microbiol. 68:3614-3621.

Chinchilla, D., Bauer, Z., Regenass, M., Boller, T. and Felix, G. 2006. The Arabidopsis receptor kinase FLS2 binds flg22 and determines the specificity of flagellin perception. Plant Cell 18:465-476.

Cooley, M. B., Miller, W. G. and Mandrell, R. E. 2003. Colonization of Arabidopsis thaliana with Salmonella enterica and enterohemorrhagic Escherichia coli O157:H7 and competition by Enterobacter asburiae. Appl. Environ. Microbiol. 69:4915-4926.

Cools, D., Merckx, R., Vlassak, K. and Verhaegen, J. 2001. Survival of E. coli and Enterococcus spp. derived from pig slurry in soils of different texture. Appl. Soil Ecol. 17:53-62.

Erickson, M. C. 2012. Internalization of fresh produce by foodborne pathogens. Annu. Rev. Food Sci. Technol. 3:283-310.

Felix, G., Duran, J. D., Volko, S. and Boller, T. 1999. Plants have a sensitive perception system for the most conserved domain of bacterial flagellin. Plant J. 18:265-276.

Franz, E., Visser, A. A., Van Diepeningen, A. D., Klerks, M. M., Termorshuizen, A. J. and van Bruggen, A. H. 2007. Quantification of contamination of lettuce by GFP-expressing 
Escherichia coli 0157:H7 and Salmonella enterica serovar Typhimurium. Food Microbiol. 24:106-112.

Gagliardi, J. V. and Karns, J. S. 2002. Persistence of Escherichia coli O157: H7 in soil and on plant roots. Environ. Microbiol. 4:89-96.

Gu, G., Hu, J., Cevallos-Cevallos, J. M., Richardson, S. M., Bartz, J. A. and van Bruggen, A. H. 2011. Internal colonization of Salmonella enterica serovar Typhimurium in tomato plants. PLoS ONE 6:e27340.

Iniguez, A. L., Dong, Y., Carter, H. D., Ahmer, B. M., Stone, J. M. and Triplett, E. W. 2005. Regulation of enteric endophytic bacterial colonization by plant defenses. Mol. Plant Microbe Interact. 18:169-178.

Islam, M., Morgan, J., Doyle, M. P., Phatak, S. C., Millner, P. and Jiang, X. 2004. Fate of Salmonella enterica serovar Typhimurium on carrots and radishes grown in fields treated with contaminated manure composts or irrigation water. Appl. Environ. Microbiol. 70:2497-2502.

Jacobsen, C. S. and Bech, T. B. 2012. Soil survival of Salmonella and transfer to freshwater and fresh produce. Food Res. Int. 45:557-566.

Jeter, C. and Matthysse, A. G. 2005. Characterization of the binding of diarrheagenic strains of $E$. coli to plant surfaces and the role of curli in the interaction of the bacteria with alfalfa sprouts. Mol. Plant Microbe Interact. 18:1235-1242.

Jones, J. D. and Dangl, J. L. 2006. The plant immune system. Nature 444:323-329.

Klerks, M. M., van Gent-Pelzer, M., Franz, E., Zijlstra, C. and van Bruggen, A. H. 2007. Physiological and molecular responses of Lactuca sativa to colonization by Salmonella enterica serovar Dublin. Appl. Environ. Microbiol. 73:49054914.

Kroupitski, Y., Golberg, D., Belausov, E., Pinto, R., Swartzberg, D., Granot, D. and Sela, S. 2009. Internalization of Salmonella enterica in leaves is induced by light and involves chemotaxis and penetration through open stomata. Appl. Environ. Microbiol. 75:6076-6086.

Kwan, G., Charkowski, A. O. and Barak, J. D. 2013. Salmonella enterica suppresses Pectobacterium carotovorum subsp. carotovorum population and soft rot progression by acidifying the microaerophilic environment. MBio 4:e0557-00512.

Lapidot, A., Romling, U. and Yaron, S. 2006. Biofilm formation and the survival of Salmonella Typhimurium on parsley. Int. J. Food Microbiol. 109:229-233.

Lapidot, A. and Yaron, S. 2009. Transfer of Salmonella enterica serovar Typhimurium from contaminated irrigation water to parsley is dependent on curli and cellulose, the biofilm matrix components. J. Food Prot. 72:618-623.

Melotto, M., Underwood, W., Koczan, J., Nomura, K. and He, S. Y. 2006. Plant stomata function in innate immunity against bacterial invasion. Cell 126:969-980.

Morris, C. E. and Monier, J.-M. 2003. The ecological significance of biofilm formation by plant-associated bacteria. Annu. Rev. Phytopathol. 41:429-453.
Nadarasah, G. and Stavrinides, J. 2011. Insects as alternative hosts for phytopathogenic bacteria. FEMS Microbiol. Rev. 35:555-575.

Natvig, E. E., Ingham, S. C., Ingham, B. H., Cooperband, L. R. and Roper, T. R. 2002. Salmonella enterica serovar Typhimurium and Escherichia coli contamination of root and leaf vegetables grown in soils with incorporated bovine manure. Appl. Environ. Microbiol. 68:2737-2744.

Nthenge, A. K., Weese, J. S., Carter, M., Wei, C. I. and Huang, T. S. 2007. Efficacy of gamma radiation and aqueous chlorine on Escherichia coli O157:H7 in hydroponically grown lettuce plants. J. Food Prot. 70:748-752.

Patel, J. and Sharma, M. 2010. Differences in attachment of Salmonella enterica serovars to cabbage and lettuce leaves. Int. J. Food Microbiol. 139:41-47.

Pollard, S., Barak, J., Boyer, R., Reiter, M., Gu, G. and Rideout, S. 2014. Potential Interactions between Salmonella enterica and Ralstonia solanacearum in Tomato Plants. J. Food Prot. 77:320-324.

Potnis, N., Soto-Arias, J. P., Cowles, K. N., van Bruggen, A. H., Jones, J. B. and Barak, J. D. 2014. Xanthomonas perforans colonization influences Salmonella enterica in the tomato phyllosphere. Appl. Environ. Microbiol. 80:3173-3180.

Poza-Carrion, C., Suslow, T. and Lindow, S. 2013. Resident bacteria on leaves enhance survival of immigrant cells of Salmonella enterica. Phytopathology 103:341-351.

Prigent-Combaret, C., Brombacher, E., Vidal, O., Ambert, A., Lejeune, P., Landini, P. and Dorel, C. 2001. Complex regulatory network controls initial adhesion and biofilm formation in Escherichia coli via regulation of the $c s g D$ gene. J. Bacteriol. 183:7213-7223.

Raina, S., Missiakas, D., Baird, L., Kumar, S. and Georgopoulos, C. 1993. Identification and transcriptional analysis of the Escherichia coli htrE operon which is homologous to pap and related pilin operons. J. Bacteriol. 175:5009-5021.

Romling, U., Sierralta, W. D., Eriksson, K. and Normark, S. 1998. Multicellular and aggregative behaviour of Salmonella typhimurium strains is controlled by mutations in the agfD promoter. Mol. Microbiol. 28:249-264.

Roy, D., Panchal, S., Rosa, B. A. and Melotto, M. 2013. Escherichia coli O157: H7 induces stronger plant immunity than Salmonella enterica Typhimurium SL1344. Phytopathology 103:326-332.

Saggers, E. J., Waspe, C. R., Parker, M. L., Waldron, K. W. and Brocklehurst, T. F. 2008. Salmonella must be viable in order to attach to the surface of prepared vegetable tissues. J. Appl. Microbiol. 105:1239-1245.

Saldana, Z., Sanchez, E., Xicohtencatl-Cortes, J., Puente, J. L. and Giron, J. A. 2011. Surface structures involved in plant stomata and leaf colonization by shiga-toxigenic Escherichia coli O157:H7. Front. Microbiol. 2:119.

Schikora, A., Carreri, A., Charpentier, E. and Hirt, H. 2008. The dark side of the salad: Salmonella typhimurium overcomes the innate immune response of Arabidopsis thaliana and 
shows an endopathogenic lifestyle. PLOS ONE 3:e2279.

Schikora, A., Garcia, A. V. and Hirt, H. 2012. Plants as alternative hosts for Salmonella. Trends Plant Sci. 17:245-249.

Schikora, A., Virlogeux-Payant, I., Bueso, E., Garcia, A. V., Nilau, T., Charrier, A., Pelletier, S., Menanteau, P., Baccarini, M. and Velge, P. 2011. Conservation of Salmonella infection mechanisms in plants and animals. PLoS ONE 6:e24112.

Semenov, A. M., Kuprianov, A. A. and Van Bruggen, A. H. 2010. Transfer of enteric pathogens to successive habitats as part of microbial cycles. Microb. Ecol. 60:239-249.

Seo, S. and Matthews, K. R. 2012. Influence of the plant defense response to Escherichia coli $\mathrm{O} 157: \mathrm{H} 7$ cell surface structures on survival of that enteric pathogen on plant surfaces. Appl. Environ. Microbiol. 78:5882-5889.

Shirron, N. and Yaron, S. 2011. Active suppression of early immune response in tobacco by the human pathogen Salmonella Typhimurium. PLoS ONE 6:e18855.

Solomon, E. B., Pang, H.-J. and Matthews, K. R. 2003. Persistence of Escherichia coli O157: H7 on lettuce plants following spray irrigation with contaminated water. J. Food Prot. 66:2198.

Solomon, E. B., Yaron, S. and Matthews, K. R. 2002. Transmission of Escherichia coli O157: H7 from contaminated manure and irrigation water to lettuce plant tissue and its subsequent internalization. Appl. Environ. Microbiol. 68:397-400.

Soto-Arias, J. P., Groves, R. and Barak, J. D. 2013. Interaction of Phytophagous Insects with Salmonella enterica on Plants and Enhanced Persistence of the Pathogen with Macrosteles quadrilineatus Infestation or Frankliniella occidentalis Feeding. PLoS ONE 8:e79404.

Spoel, S. H. and Dong, X. 2012. How do plants achieve immunity? Defense without specialized immune cells. Nat. Rev. Immunol. 12:89-100.
Stenström, T. A. 1989. Bacterial hydrophobicity, an overall parameter for the measurement of adhesion potential to soil particles. Appl. Environ. Microbiol. 55:142-147.

Stine, S. W., Song, I., Choi, C. Y. and Gerba, C. P. 2005. Effect of relative humidity on preharvest survival of bacterial and viral pathogens on the surface of cantaloupe, lettuce, and bell peppers. J. Food Prot. 68:1352-1358.

Thilmony, R., Underwood, W. and He, S. Y. 2006. Genome-wide transcriptional analysis of the Arabidopsis thaliana interaction with the plant pathogen Pseudomonas syringae pv. tomato DC3000 and the human pathogen Escherichia coli O157: H7. Plant J. 46:34-53.

Thomason, B. M., Dodd, D. J. and Cherry, W. B. 1977. Increased recovery of salmonellae from environmental samples enriched with buffered peptone water. Appl. Environ. Microbiol. 34:270-273.

Wasala, L., Talley, J. L., DeSilva, U., Fletcher, J. and Wayadande, A. 2013. Transfer of Escherichia coli O157: H7 to spinach by house flies, Musca domestica (Diptera: Muscidae). Phytopathology 103:373-380.

Wells, J. and Butterfield, J. 1997. Salmonella contamination associated with bacterial soft rot of fresh fruits and vegetables in the marketplace. Plant Dis. 81:867-872.

Wells, J. and Butterfield, J. 1999. Incidence of Salmonella on fresh fruits and vegetables affected by fungal rots or physical injury. Plant Dis. 83:722-726.

Williams, A., Avery, L., Killham, K. and Jones, D. 2007. Survival of Escherichia coli O157: $\mathrm{H} 7$ in the rhizosphere of maize grown in waste-amended soil. J. Appl. Microbiol. 102:319326.

Zeng, W., Melotto, M. and He, S. Y. 2010. Plant stomata: a checkpoint of host immunity and pathogen virulence. Curr. Opin. Biotechnol. 21:599-603. 